\title{
Educação ambiental e os resíduos eletrônicos: Percepções de estudantes do ensino médio de Soure, Pará, Brasil
}

Environmental education and waste electronics: Perceptions of high school of students of Soure, Pará, Brazil

\author{
G. K. S. Carvalho ${ }^{1 *}$; M. S. Espirito Santo ${ }^{1}$; L. O. Souza²; V. W. B. Diniz ; R. F. \\ Souza $^{3}$ \\ ${ }^{1}$ Curso de Ciências Naturais com habilitação em Química, Campus XIX-Salvaterra, Universidade do Estado do \\ Pará, 68860-000, Salvaterra-PA, Brasil
}

${ }^{2}$ Engenheira Sanitarista e Ambiental, Universidade Federal do Pará, Belém-PA, Brasil

${ }^{3}$ Departamento de Ciências Naturais/Grupo de Pesquisa em Química, Ensino de Química e Meio Ambiente, Campus XIX-Salvaterra, Universidade do Estado do Pará, 68860-000, Salvaterra-PA, Brasil

*gizelykerolaine@outlook.com

(Recebido em 08 de abril de 2016; aceito em 05 de maio de 2016)

\begin{abstract}
A contaminação dos solos por metais pesados nos centros urbanos podem ser proveniente de descarte do lixo eletrônico depositado em locais inapropriados. O presente estudo teve como objetivo investigar o grau de conhecimento dos alunos do $1^{\circ}$ ano do ensino médio nas escolas públicas do município de Soure, Pará, sobre as consequências da contaminação do meio ambiente por metais pesados, quando provenientes do lixo eletrônico. O trabalho foi realizado em três escolas estaduais de ensino médio e envolveu 337 alunos do primeiro ano. $\mathrm{O}$ instrumento de coleta de dados utilizado foi o questionário. Os resultados mostraram que grande parte dos alunos tem conhecimento limitado sobre o tema em questão. Observou-se que a partir do momento de intervenção os alunos voltaram sua atenção sobre os metais pesados e a conservação do meio ambiente, visando alcançar uma sociedade mais sustentável.
\end{abstract}

Palavras-chave: Ensino de química, Metais pesados, Educação ambiental

Contamination of soils by heavy metals in urban center can be descendant of the discard of electronic trash deposited in unbecoming places. The present study had as object investigated the degree of knowledge of the first year high school students in public schools in the municipality of Soure, Pará. About the consequences of the contamination by heavy metals, when descendant of the electronic trash. The work was realized in three schools and enwrapped 337 student of first grade. The device of data collections used was the questionnaire the results to show that majority of involved students in this research have a restricted knowledge about the theme. Observed that from the intervention time the students back their attentions about the slowpoke metals and the conservation of the environment direct achieve a community more resistant.

Keywords: Chemical education, Heavy metals, Environmental education

\section{INTRODUÇÃO}

O uso exagerado de recursos naturais carrega consigo outro problema: a produção de resíduos; que na maioria das vezes não recebem uma destinação final ambientalmente correta ocasionando diversos impactos ambientais [1].

A sociedade moderna produz dejetos em tal quantidade e velocidade que contribuem consideravelmente para sérios danos ambientais, agravados quando a cidade apresenta deficiência de infraestrutura, principalmente no que tange a coleta de lixo seletiva e a falta de informação por parte da comunidade em relação ao descarte adequado de resíduos, inclusive o eletrônico. Entretanto, nas mediações da cidade de Soure é notório a disposição inadequada dos rejeitos oriundos de residências, comércio, oficinas, logradouros públicos, entre outros [2], tendo o solo como destino final no chamado lixão a céu aberto.

Dentre os diversos tipos de resíduos sólidos inerentes à uma sociedade consumidora, a produção e o descarte de lixo eletrônico junto a resíduos sólidos comuns dentro da cidade é preocupante, pois em sua composição existem elementos inorgânicos nocivos ao meio ambiente, como os metais pesados. O lixo eletrônico sendo depositado em áreas impróprias ou 
despejados arbitrariamente ao solo sem qualquer tratamento, afeta diretamente o equilíbrio ambiental, com a possibilidade de contaminação no solo, lençol freático, sistema hídrico e vegetação, além de caracterizar um problema de saúde pública [3].

$\mathrm{O}$ risco de contaminação do meio ambiente por metais pesados aumenta à medida que a falta de informação das pessoas quanto à destinação correta de alguns de rejeitos, favorece a falta de controle na geração de materiais nocivos despejados no ambiente [4].

Neste contexto a população como um todo precisa se sensibilizar com esta temática e buscar alternativas para amenizar este problema. A escola é uma fonte que produz e dissemina conhecimento técnico e científicos, portanto, pode ser tomada como um ponto de partida de conhecimento para sensibilizar e posteriormente conscientizar um grande numero de pessoas. Em seu estudo, Pereira et al. [5] relatam que os alunos aproveitam melhor as discussões em sala de aula, pois trazem consigo conhecimentos adquiridos no cotidiano que favorecem a formação de opiniões relacionadas à sustentabilidade da vida no planeta. Esta afirmação reforça o papel da escola como um dos meios indispensáveis para se conseguir criar e aplicar formas cada vez mais sustentáveis de interação entre a sociedade e a natureza, bem como na busca de soluções para os problemas ambientais, portanto, a Educação Ambiental nas escolas é um recurso indispensável para a formação completa de indivíduos conscientes [6].

Este trabalho visou investigar o grau de conhecimento dos alunos do $1^{\circ}$ ano do ensino médio das escolas do município de Soure-PA, sobre as ameaças dos metais pesados, provenientes de lixo eletrônico, quando em contato com solo. Buscou-se informar a importância de se descartar corretamente este rejeito, estimulando atitudes ambientalmente correta sobre o problema através de um projeto de intervenção.

\section{MATERIAL E MÉTODOS}

O trabalho foi desenvolvido no município de Soure-PA, onde existem nove escolas públicas. Destas, três são de ensino médio e seis de ensino fundamental. Participaram da coleta de dados 337 estudantes das três escolas estaduais, sendo todos do $1^{\circ}$ ano do ensino médio (Escolas $\mathrm{A} \mathrm{n}=$ 80 alunos, $\mathrm{B} \mathrm{n}=111$ alunos e $\mathrm{C} \mathrm{n}=146$ alunos). Os encontros foram realizados em dois períodos: o primeiro ocorreu durante o mês de Março/2015 para aplicação de questionários e o segundo no mês de Agosto/2015 com a realização de um projeto de intervenção.

No primeiro momento aplicou-se o questionário onde sua elaboração seguiu orientações de Cohen et al. [7], as questões aplicadas foram direcionadas para avaliação das concepções dos alunos evolvidos acerca do tema metais pesados.

Após a aplicação do questionário e com base nos dados obtidos, realizou-se um trabalho de intervenção, voltado às dificuldades identificadas nas turmas de primeiro ano do turno da manhã da escola A, uma vez que seus alunos apresentaram o maior déficit de conhecimentos acerca do tema desta pesquisa. Diante disso, para a aplicação do projeto, adotou-se o seguinte procedimento metodológico:

1. Palestra: Utilizou-se para a atividade uma palestra educativa (Figura 1) envolvendo temas importantes na construção de novos conceitos ambientais com intuito de problematizar a realidade da cidade em relação ao descarte e acúmulo de residuos sólidos depositado inadequadamente no solo. 


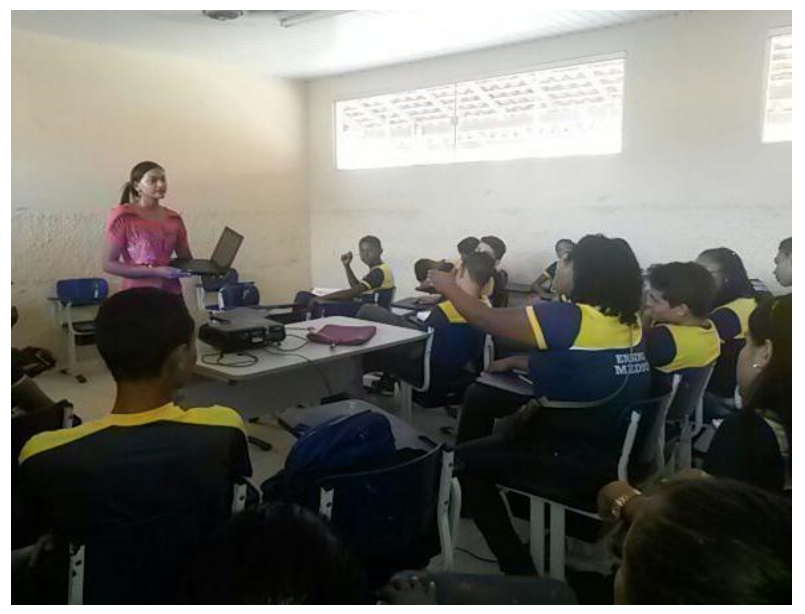

Figura 1: Momento de interação entre aluno e pesquisadora na atividade de intervenção

No decorrer da palestra vários conteúdos envolvendo lixo tecnológico e metais pesados foram sendo abordados com auxílio de imagens e vídeos, dando ênfase nas definições e tipos de metais pesados contidos no lixo tecnológico; contaminação; danos causados ao solo, a água e ao homem; formas de descartes e outros.

2. Confecção de lixeiras ecológicas: Foi realizada uma atividade prática com os alunos como maneira de inserir o educando na participação da busca de alternativas que colaborem para a mudança de hábitos, amenização dos efeitos negativos de práticas ambientalmente inadequadas no ecossistema e envolvê-los em uma nova postura ambiental mediante a confecção de lixeiras educativas.

A proposta desta atividade prática visou a produção de quatro lixeiras destinadas para: pilhas e baterias, papel, vidro, plástico, tendo como finalidade de selecioná-los.

Os materiais utilizados foram: cola, papel carmim (verde, azul, amarelo e vermelho), tesoura, fita adesiva, caneta pincel, papel sem pauta, saco para lixo, caixa de papelão (Figura 2). As lixeiras produzidas foram disponibilizadas para a escola (Figuras 3 e 4).

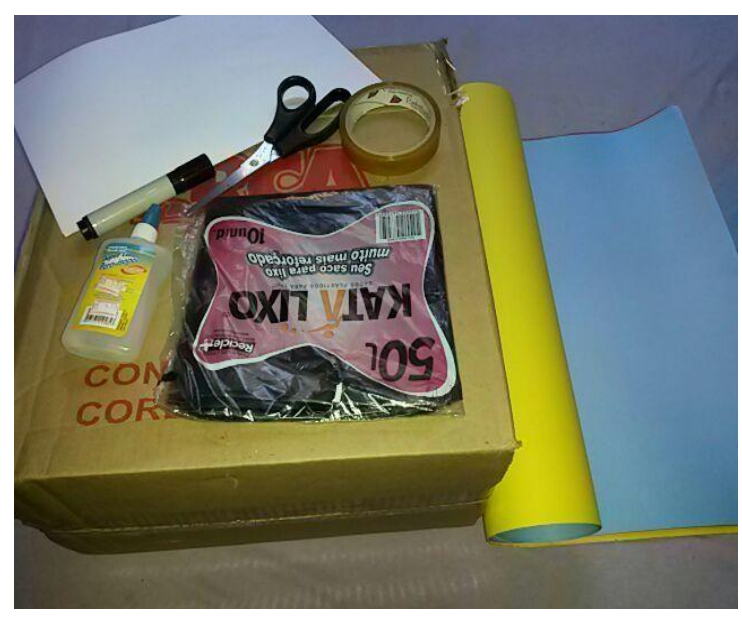

Figura 2: Materiais utilizados na produção das lixeiras 


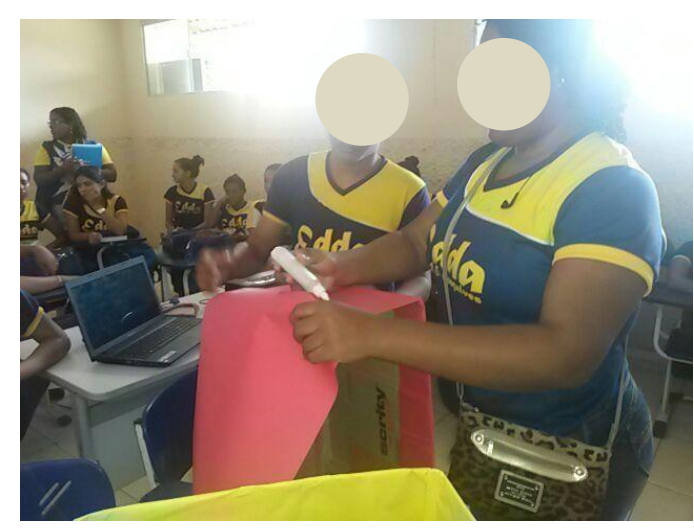

Figura 3: Confecção das lixeiras

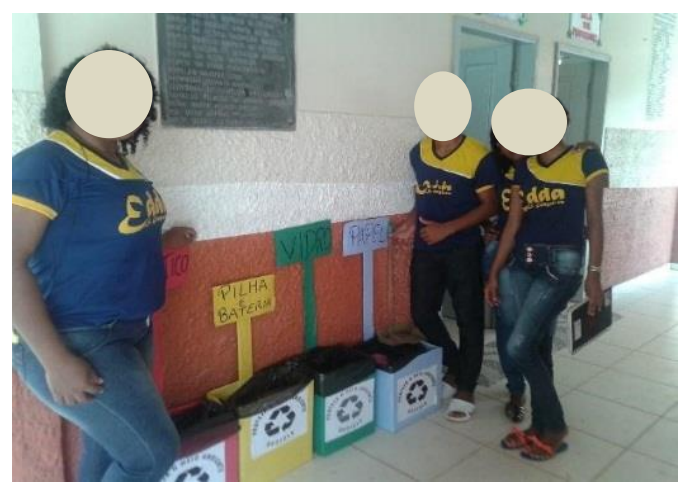

Figura 4: Lixeiras finalizadas e disponibilizadas no corredor da escola.

Assim como na maioria das cidades, o município de Soure não dispõe de pontos de coleta e reciclagem para o lixo tecnológico, tendo em vista esta falta de infraestrutura, ficou acordado com a direção da escola que conforme a lixeira destinada às pilhas e baterias for enchendo, este resíduo será recolhido pelos pesquisadores (G. K. S. Carvalho e M. S. Espirito Santo) e imediatamente encaminhado para Belém, Pará à uma empresa especializada no descarte correto do material. E a partir do segundo momento, caberia à instituição de ensino zelar, recolher e encaminhar este lixo para a referida empresa.

2. Produção de texto: Com o objetivo de analisar a efetividade dos efeitos do projeto de intervenção, foi proposto aos educandos que elaborassem um texto dissertativo, descrevendo os conhecimentos adquiridos durante o desenvolvimento das atividades (Figura 5). A interpretação após a coleta dos dados foi realizada utilizando a técnica análise de conteúdo [8].

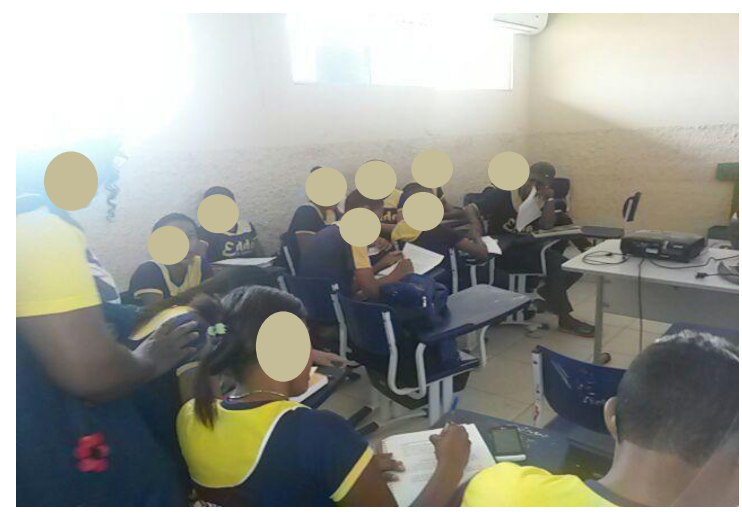

Figura 5: Atividade avaliativa e produção de texto 


\section{RESULTADOS E DISCUSSÃO}

A aplicação dos questionários realizado na etapa de diagnóstico entre os alunos foi feita de forma aleatória, distinguindo apenas entre escolas pequisadas.

Na primeira pergunta, questinou-se sobre onde eles costumam descartar os materiais, como pilhas e baterias. Observou-se que $87 \%$ dos alunos da escola A, 76\% dos alunos da escola B e $53 \%$ da escola $\mathrm{C}$ descartam estes rejeitos na lixeira de sua própria casa, e destaca-se que $34 \%$ dos alunos da escola $\mathrm{C}$ descarta este estipo de resíduo na rua (Figura 6).

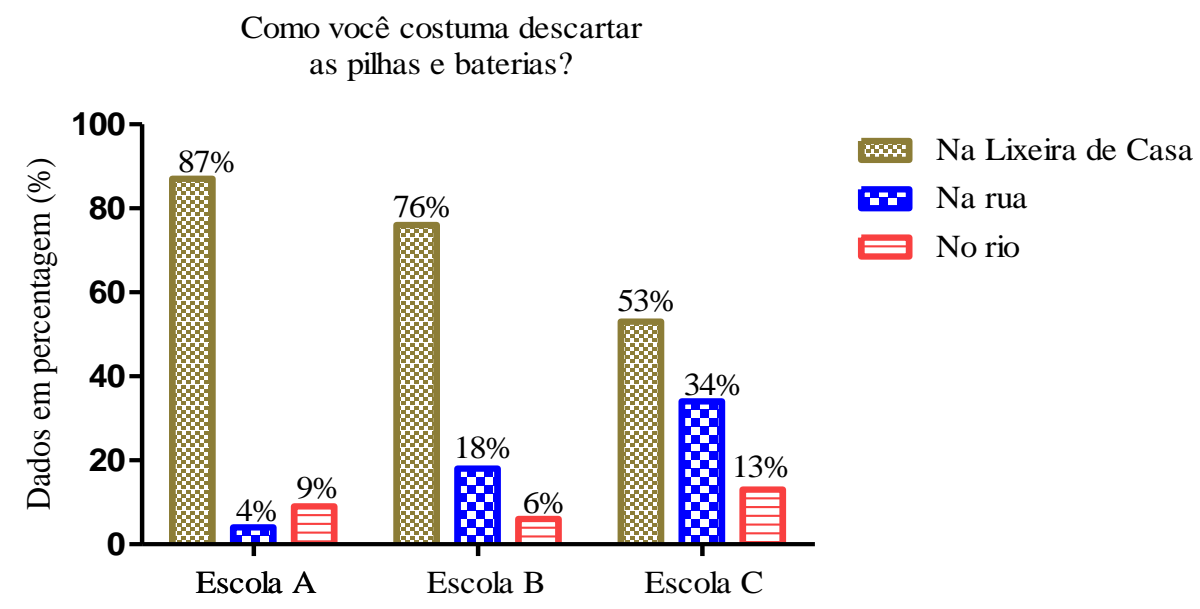

Figura 6: Pergunta $n^{\circ} 01$ aplicado aos alunos das escolas A, B e C

A Figura 7 apresenta a variação entre os alunos das escolas A, B e C, sobre o conhecimento que estes possuem sobre $\mathrm{o}$ assunto metais pesados.

Você conhece os metais que constituem as pilhas e baterias?

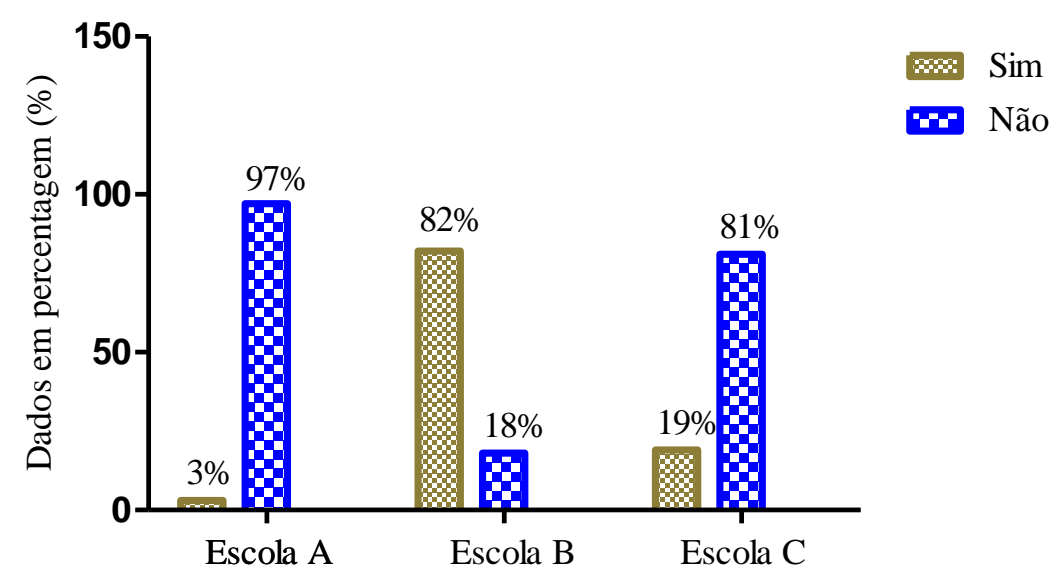

Figura 7: Pergunta $n^{\circ} 02$ aplicado aos alunos das escolas A, B e C

Observou-se que $97 \%$ dos alunos da escola A e $81 \%$ da escola C, não conhecem os metais que constituem as pilhas e baterias. Enquanto $82 \%$ dos alunos da escola B possuiem conhecimento sobre os metais que constituem as pelhas e bactérias (Figura 7).

Ao responder sobre os riscos causados pelo descarte do lixo eletrônico, $80 \%$ dos alunos da escola A conhecem estes riscos (Figura 8), porém adotam a lixeira de suas casas como principal 
destino (Figura 6) e posteriormente, são descartados no lixão a céu aberto localizado nas proximidades da cidade. Os alunos das escolas B e $\mathrm{C}$ apresentaram opiniões similares quanto a este questionamento (Figura 8).

Você conhece os riscos causados pelo descarte do lixo eletrônico no meio ambiente?

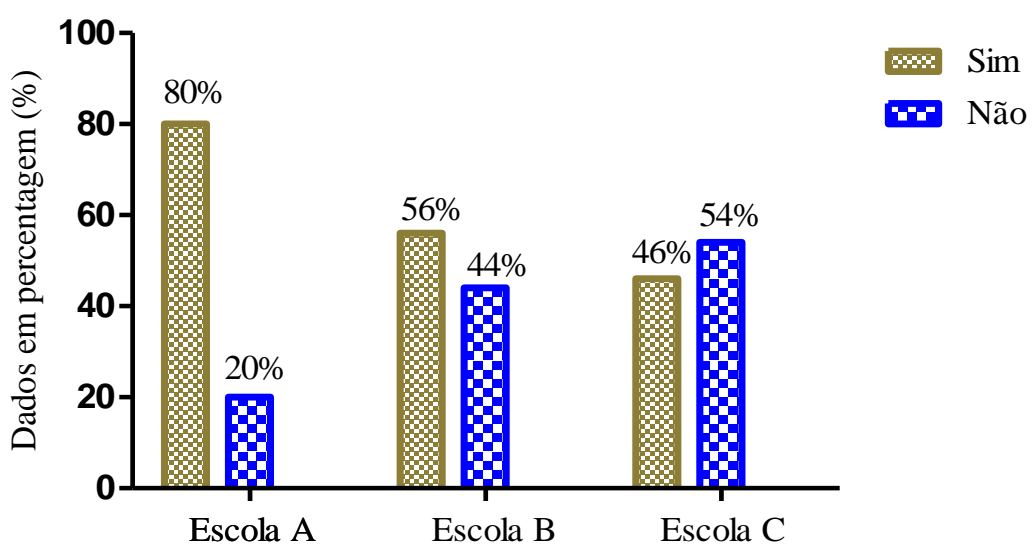

Figura 8: Pergunta $n^{\circ} 03$ aplicado aos alunos das escolas A, B e C

Os alunos também foram questionados sobre elementos que eles consideram ser metais pesados, para tanto, disponibilizou-se cinco opções de respostas e notou-se que todos os alunos mencionaram o elemento chumbo seguido do elemento ferro (Figura 9). Estes resultados demostram que a maioria dos alunos trazem consigo conhecimentos adquiridos algum meio de informação presente no seu cotidiano que favorecem a formação de opiniões relacionadas ao entendimento do termo metal pesado.

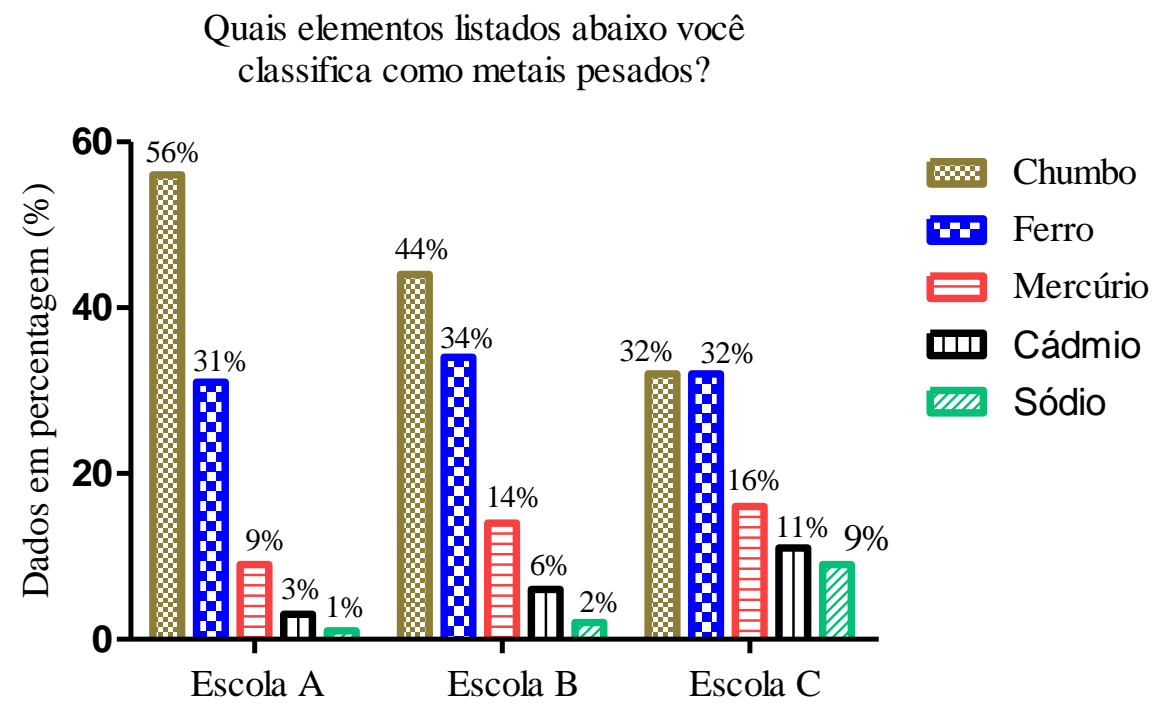

Figura 9: Pergunta $n^{\circ} 04$ aplicado aos alunos das escolas A, B e C

Quando indagados se haviam estudado sobre metais pesados, 93\% dos alunos da escola A afirmaram que nunca haviam estudado, enquanto $7 \%$ disseram que sim. Na escola B, $87 \%$ dos alunos disseram que estudaram o tema nas suas aulas de química (Figura 10). Portanto, observa- 
se que temas importantes de interesse amplo não vem sendo abordadas nas escolas durante as aulas de química.

[...] "Levando-se em consideração que a conceituação de metal e questões envolvendo química e meio ambiente são temas abordados no ensino médio, os metais pesados podem se tornar um importante tema contextualizador no ensino de química" [9].

Você estudou sobre os metais

pesados em suas aulas de química?

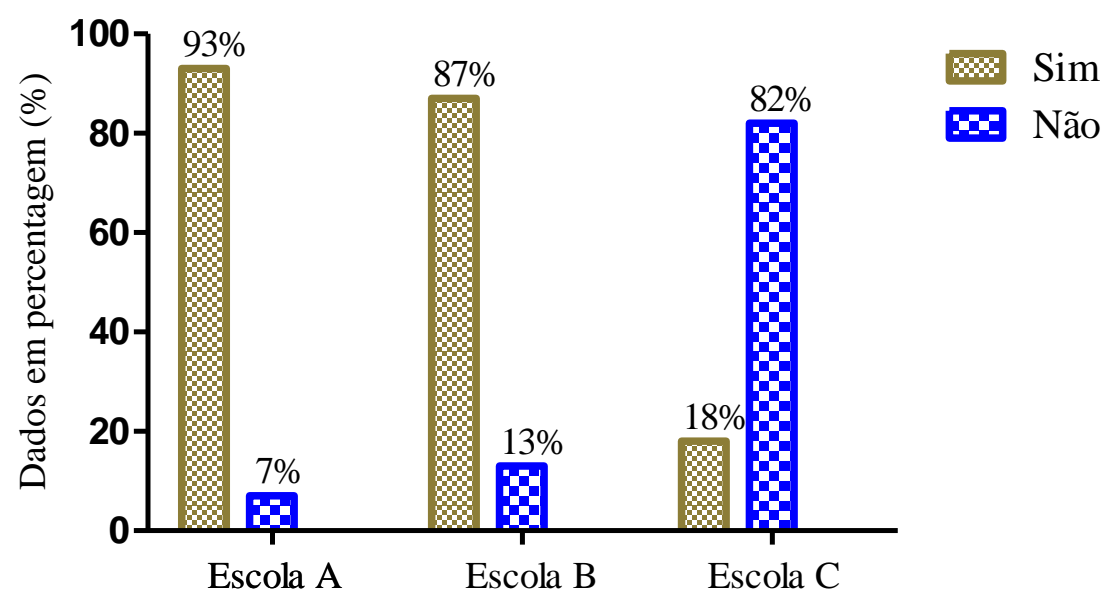

Figura 10: Pergunta $n^{\circ} 05$ aplicado aos alunos das escolas A, B e C

Os resultados evidenciam que os conhecimentos dos alunos sobre a contaminação do meio ambiente por metais pesados provenientes do lixo eletrônico nas escolas do município de SourePA é limitado no que tange o entendimento dos conceitos e definições do metais pesados. Observou-se também a falta de abordagem deste tema durante as aulas de química. Por isso, optou-se então por desenvolver uma metodologia que levasse em consideração os princípios básicos da Educação Ambiental com os alunos da escola A.

[...] A educação ambiental influencia o despertar de uma mentalidade voltada para a preservação da natureza e a promoção do desenvolvimento sustentável e quais os impactos que este despertar pode provocar no futuro. $\mathrm{O}$ tema é de grande relevância visto que a cada dia que passa o meio ambiente é mais agredido pela ação do homem e somente através da conscientização desde cedo das crianças será possível criar uma sociedade que valorize o meio ambiente e participe ativamente das ações desenvolvidas para preservá-lo [10].

Neste contexto, a proposta de intervenção aplicada permitiu a reflexão sobre as consequências do constante avanço tecnológico e, auxiliou a desenvolver estratégias de ensino que contribuam para a formação de conceitos críticos e a inserção de hábitos saudáveis, uma vez que, no momento em que os discentes adquirem novos conhecimentos, isso irá proporcionar a sensibilização da nova geração com a responsabilidade ambiental no descarte desses materiais e preocupados com a saúde ambiental de sua região.

No desenvolvimento da atividade de intervenção, o interesse dos alunos foi notado em algumas falas, transcritas literalmente, como:

"Agora fiquei preocupada porque eu enterro as pilhas no chão",

(Aluno A)

"Nossa! Lá perto de casa tem um monte de televisão jogada" 


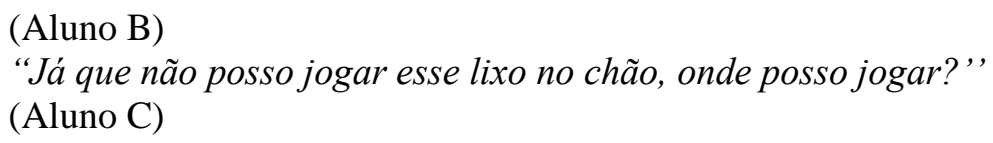

Um comentário de um aluno, mostra que as informações repassadas e discutidos no âmbito deste trabalho foram importantes para o entendimento da problemática ambiental observada na cidade.

"Agora quando eu ver eles jogarem estes lixos lá perto de casa, eu vou chamar a atenção deles" (Aluno D)

Embora muito se fale em evolução, um fato relevante vivenciado no dia-a-dia do município de Soure-PA é a maneira como é feita a coleta de lixo nas residências e em pontos comerciais da cidade, onde qualquer tipo de rejeito é descartado em sacos de lixo pela população e em seguida coletados por catadores (Figura 11) que despejam este material no lixão (Figura 12).

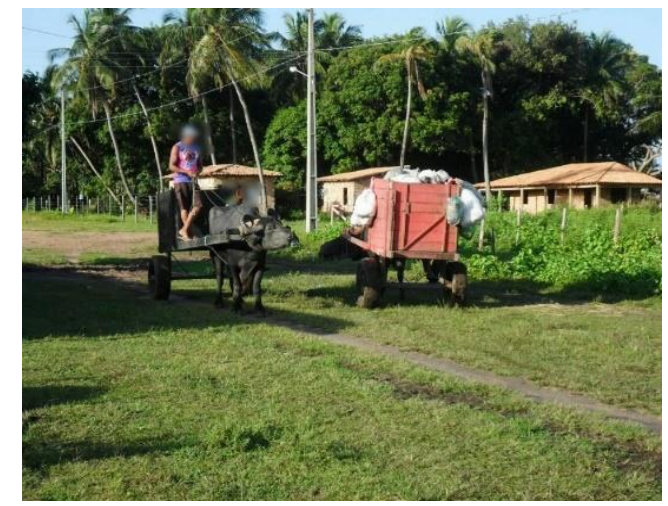

Figura 11: Coleta de lixo em residências

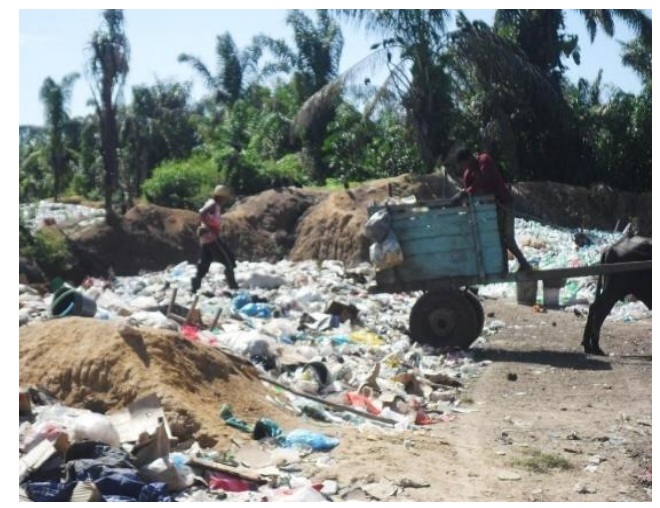

Figura 12: Lixo coletado nas residências sendo depositado no lixão

Com o propósito de inserir o aluno nas variadas dimensões desta problemática e motivar sua participação neste processo contínuo de formação para construção de uma sociedade sustentável, foi proposto a produção e disponibilização de lixeiras para a coleta seletiva em cada uma das escolas.

Desta forma, percebeu-se que envolvendo os alunos em atividades práticas, os resultados são satisfatórios à medida que tal engajamento é feito de maneira atrativa e dinâmica, com o objetivo não apenas de aproximá-los aos problemas ambientais enfrentados por sua sociedade, mas também inseri-los na construção de novos conceitos e ideias pautadas nos princípios da Educação Ambiental.

Os alunos produziram textos após a aplicação da aula com a temática ambiental. Alguns trechos são transcritos a seguir.

"Os metais pesados podem causar sérios problemas para o ser humano é para a natureza, pois contaminam o solo e a água. Por isso não devemos Jogar pilhas e baterias de celulares em qualquer lugar". (Aluno E)

"O lixo eletrônico quando é descartado incorretamente no solo poderá contaminar o lençol freático através dos metais pesados e assim causar sérios problemas de saúde para nós" (Aluno F)

É conveniente admitir que a partir do momento em que a escola, em uma ação integrada com os professores, passar a articular ações educativas voltadas para a discução de temas abordando problemas ambientais comuns na realidade local, obtem-se melhores resultados frente à reflexão destes alunos enquanto indivíduos sensibilizados e conscientes de seus atos diante da natureza e sociedade. 
[...], A educação ambiental possibilitará novos rumos ao meio ambiente, contanto que os professores sejam mediadores para formar alunos críticos, conscientes e responsáveis. É por meio da práxis, ou seja, ação-reflexão ação, que poderemos chegar a uma consciência crítica, capaz de perceber os problemas ambientais e refletir sobre o que estamos fazendo para proteger o meio ambiente [11].

Diante dos resutados, foi possível perceber a importância da realização de práticas nas escolas, pois auxiliam no ensino aprendizagem e despertam o interesse da maioria dos alunos, além de facilitar a aproximação destes com a realidade ambiental local.

\section{CONCLUSÃO}

No desenvolvimento de todo o estudo foi possível constatar a concepção dos alunos de nove turmas de primeiro ano do ensino médio de três escolas estaduais públicas da cidade de SourePA, sobre o tema metais pesados e os riscos que eles causam ao meio ambiente quando proveniente do lixo eletrônico. No estudo de diagnóstico obteve-se resultados preocupantes, uma vez que havia um considerável número de alunos com pouco conhecimento sobre o tema em questão e consequentemente reflete na realidade encontrada na cidade. No momento da intervenção na escola foi possível discutir os conhecimentos prévios dos alunos sobre o tema metais pesados e acrescentar informações necessárias sobre o descarte correto do lixo eletrônico e sua problemática ambiental. Destaca-se ainda a contribuição deste estudo, no despertar do interesse dos alunos em querer proteger o meio ambiente urbano, disseminando as informações no seu meio de convívio. Uma sugestão é que este tipo de atividade possa ser adotada em todas as escolas do município de Soure-PA.

\section{REFERÊNCIAS BIBLIOGRÁFICAS}

1. Jardim VL, Fofonka L. Educação ambiental e gestão dos resíduos sólidos da construção e demolição no município de Canoas/RS. Revista Educação Ambiental em Ação 2013 jun/ago; 44(XII). Disponível em http://www.revistaea.org/artigo.php?idartigo=1485, acessado em 08/04/2016.

2. Alencar MMM. Reciclagem de lixo numa escola pública do município de salvador. Candombá Revista Virtual 2005 jul/Dez;1(2):96 -113.

3. Nascentes, C. Poluição ambiental por metais. Ambiental sustentável. 2012 Fev. Disponível em http://ambientalsustentavel.org/2012/poluicao-ambiental-por-metais/, acessado em 08/04/2016.

4. Bertoldo M, Chies C, Rodrigues B, Silva J. Resíduos sólidos:problemáticas associadas ao lixo eletrônico e a reciclagem em campo mourão - PR. ln: simpósio de estudos urbanos: A dinâmica das cidades e a produção do espaço; 2013 Ago 19-21; Campo Mourão. 2013. p. 01-11.

5. Pereira CG, Silva LF, Souza LO, Souza RF. Um estudo diagnóstico sobre educação ambiental nas escolas do ensino fundamental e médio de São Miguel do Guamá-Pará. Enciclopédia Biosfera 2014;10(19):2558-2566.

6. Oliveira MS, Oliveira BS, Vilela MCS, Castro TAA. A importância da educação ambiental na escola e a reciclagem do lixo orgânico. Revista Científica Eletrônica de Ciências sociais aplicadas da Eduvale 2012 nov; 5(7):1-20.

7. Cohen L, Manion L, Morrison K. Research Methods in Education, 7 ed. New York: Routledge, 2011.

8. Severino AJ. Metodologia do trabalho científico. 23. ed. rev. e atual. São Paulo: Cortez, 2007.

9. Lima VF, Merçon, F. Metais Pesados no Ensino de Química. Química nova na escola 2011 nov;33(4):199-204.

10. Paula, ELS. Educação ambiental em sala de aula [Trabalho Monográfico]. Rio de Janeiro: Universidade Cândido Mendes (UCAM); 2010. 36 p.

11. Knorst PAR. Educação Ambiental: um desafio para as unidades escolares. Unoesc \& Ciência ACHS 2010 jul/dez;1(2):131-138. 